\section{Conclusions}

The focus on premarital carrier matching was presented in this study as the result of a community-based and culturesensitive process. Embedding genetic counselling in the Bedouin community was done for the purpose of marriage and family planning, and is expected to lead eventually to a reduction in the prevalence of affected babies. It remains to be seen whether, in the Bedouin setting, an incompatible result derived from premarital carrier matching would indeed be acted upon. Further research is needed to explore the actual uptake of the genetic counselling service and its use in the decision-making process as regards marriage, family planning and reproduction.

\section{Acknowledgements}

The authors wish to thank all the Bedouin respondents and genetic counsellors who participated in this study. They are also indebted to the anonymous journal reviewers for their useful comments. The authors would like to acknowledge the co-operation of two co-investigators who initiated and oversaw the project described here and who were responsible for the tremendous genetic and epidemiological work that preceded this project, namely Profs Ilana Shoham-Vardi and Rivka Carmi.
Statements on funding and competing interests

Funding. This study was funded by grants from the Israel Foundation Trustees (Project PS14/3) and the Israel Science Foundation (Grant 769/00-2).

Competing interests. None identified.

References

1 Weitzman D, Shoham-Vardi I, Elbedour K, et al. Factors affecting utilization of prenatal testing for fetal abnormalities in a traditional society. Community Genet 2000; 3: 45-92.

2 Lewando-Hundt G, Shoham-Vardi I, Beckerelg I, et al. Knowledge, action and resistance: the selective use of prenatal screening among Bedouin women of the Negev, Israel. Soc Sci Med 2001; 52: 561-569.

3 Davidov B, Goldman B, Akstein E, et al. Prenatal testing for Down syndrome in the Jewish and non-Jewish populations in Israel. Isr $J$ Med Sci 1994; 30: 629-633.

4 Carmi R, Elbedour K, Weitzman D, et al. Lowering the burden of hereditary diseases in a traditional inbred community: ethical aspects of genetic research and its application. Sci Context 1998; 11(3-4): 391-395.

5 Ekstein J, Katzenstein H. The Dor Yeshorim story: community-based carrier screening for Tay-Sachs disease. Adv Genet 2001; 44: $297-310$

\title{
SERVICE DELIVERY
}

\section{Decision making and referral prior to abortion: a qualitative study of women's experiences}

\author{
Usha Kumar, MRCOG, DFFP, Specialist Registrar; Paula Baraitser, MB BS, MFFP, SCMO; Sheila Morton, RGN, RM, Women's \\ Health Researcher; Helen Massil, MRCOG, MFFP, Consultant, Department of Sexual and Reproductive Health, Southwark \\ Primary Care Trust, London, UK
}

Correspondence: Dr Usha Kumar, Department of Sexual and Reproductive Health, Southwark Primary Care Trust, St Giles Hospital, St Giles Road, London SE5 7RN, UK. E-mail: akumar5902@aol.com

(Accepted 21 October 2003)

Journal of Family Planning and Reproductive Health Care 2004; 30(1): 51-54

\begin{abstract}
Background. Despite abortion being one of the most common gynaecological procedures performed in the UK, significant regional variation exists in access to services. Objective. This study explores women's experience of referral for abortion in three inner London boroughs to determine if services met their expectations.

Method. In-depth interviews conducted with 21 women of varying ages, gestations and ethnicity, 3-9 weeks after termination of their pregnancy. The data were subjected to qualitative analysis.

Results. Most women had made a decision to proceed with abortion before approaching the health service, and expected non-judgemental support, information and prompt referral. We found variations in the extent to which these expectations were met. Delays in referral occurred when health professionals either required women to have more thinking time, referred them elsewhere for pregnancy testing or avoided discussing abortion. This was further compounded by difficulties in making appointments via the centralised telephone booking service. The brief counselling session offered to most women by the abortion providers, although helpful to some women, was viewed as unnecessary and intrusive by others.

Conclusions. Most women seeking an abortion prefer not to discuss their decision but expect information and prompt referral. Delays in referral cause distress and later abortions and should be avoided. High-quality counselling should be targeted at those in need.
\end{abstract}

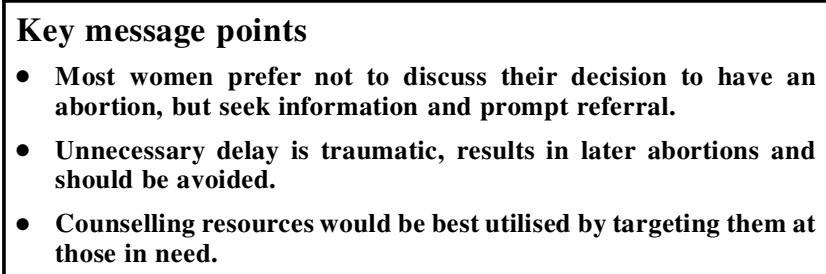

\section{Introduction}

Induced abortion is one of the most common gynaecological operations performed in Great Britain with one in three women undergoing an abortion by the age of 45 years. ${ }^{1,2}$ The Royal College of Obstetricians and Gynaecologists (RCOG) guidelines on 'The Care of Women Requesting Abortion' sets quality standards for abortion services but there remains significant regional variation in access to and quality of services provided. 1,3,4

The National Health Service (NHS) Plan requires each NHS Trust in England to obtain feedback from patients about their experiences of care ${ }^{5}$ but there has been little work to date on women's experience of abortion services. Questionnaire surveys provide some information ${ }^{6-9}$ but cannot provide a detailed account of women's experience of this procedure, and in-depth qualitative data are scarce. ${ }^{10-12}$ Data on the experience of women using the NHS abortion service in three inner London boroughs are presented, from the time the women suspected that they were pregnant until their first visit for assessment prior to the abortion procedure. 


\section{Background}

The area under study is characterised by an ethnically diverse population with significant levels of deprivation, high fertility and abortion rates. NHS abortion services are provided by an acute NHS Trust and two voluntary sector organisations. Appointments for assessment prior to termination of pregnancy (TOP) are made via a common telephone booking service which can be accessed by clients either directly, or via general practitioners (GPs), family planning clinics (FPCs), Brook clinics and genitourinary medicine (GUM) clinics.

\section{Method}

\section{Recruitment and sampling}

Study participants were recruited at the time of their visit to the TOP assessment clinic following their consultation with the doctor. They were recruited from each of the three TOP provider units. Only those obtaining an abortion within the NHS and living in the three boroughs under study were recruited. Non-English speaking clients were excluded due to difficulties anticipated in interviewing and transcribing of data.

After applying the above criteria for inclusion and exclusion, a convenience sample of women was recruited. The nature and purpose of the study was explained, written information provided and written consent obtained. Those willing to participate were contacted 1-2 weeks after their TOP and invited to an interview. These were conducted 3-6 weeks post-TOP in all instances except for two clients, who were interviewed 9 weeks post-abortion, as earlier dates were inconvenient for them. Prior to the interview, written consent was obtained again. One researcher (S.M.) carried out all the interviews. Two local research and ethics committees approved the study.

When the study was designed the sample size planned was 20. Such non-probability sampling is considered appropriate in qualitative studies where the intention is not to demonstrate any statistical representativeness, but to represent salient population characteristics. ${ }^{13}$ Due to anticipation of high dropout rates given the sensitive nature of the subject, initial contact and consent for participation was obtained from 64 women. Of these, admission for TOP was not confirmed in three women; 14 could not be contacted after their TOP despite many attempts; 10 withdrew from the study after their TOP (one woman was emotionally upset, one had moved out of the area and the others did not give reasons) and 16 did not attend their scheduled interviews.

\section{Data collection}

Twenty-one women aged between 16 and 40 years with pregnancies of 7-15 weeks were interviewed. Data were collected between September 2001 and August 2002.

The interviews were in-depth, semi-structured and based on a topic guide. They covered the events from when the women first suspected that they were pregnant to the postabortion period. These interviews were structured by a list of open-ended questions that defined the area to be explored, from which the interviewer or interviewee could diverge in order to pursue any idea or response in more detail. ${ }^{14}$ The interviews took place either in clients' homes, or in the offices of the Department of Sexual and Reproductive Health, and lasted between 1 and 2 hours. The interviews were tape-recorded and transcribed verbatim. During the process of data collection, the interview schedule was adapted to test emerging themes. Participants could terminate the interview at any stage if psychologically distressed, and one participant did so after 15 minutes. The researcher directed clients who requested counselling following their interview to appropriate support services.
Analysis

The data were analysed using a 'framework approach' of systematic sifting, charting and sorting of data according to key issues and themes. ${ }^{15,16}$ Familiarisation with the data was gained by listening to the tapes and reading the transcripts as the data came in. While reviewing the material, notes were made independently by two researchers (U.K. and P.B.) listing the key ideas and recurrent themes that emerged. There was general agreement between the researchers on the themes that were identified. The interview instrument was adapted further to gain in-depth information on the issues identified during this preliminary analysis.

The transcripts were coded according to the key themes generated. Sections of transcripts relating to each theme were grouped together and analysed to generate hypotheses. The validity of these was tested by systematically searching each dataset looking for deviant cases and modifying or refuting the hypotheses during the process. This was completed independently by two researchers (U.K. and P.B.) who met regularly to discuss their results. There was a high level of agreement between the separate analyses and the data were rechecked to resolve any points of disagreement.

\section{Results}

Of the 21 women who participated, six were recruited from the acute NHS Hospital Trust, with seven and eight women from each of the voluntary sector abortion providers. A total of 14/21 women interviewed identified themselves as from an ethnic minority. The ages of the respondents are given in Table 1.

This paper presents the results that relate to the decision-making process, counselling and referral prior to abortion. Further information from this study, regarding provision of peri-abortion contraceptive counselling, is provided in an accompanying paper. ${ }^{17}$

\section{Making the decision}

The reasons stated by women for choosing an abortion included an inability to care for a child (for financial reasons or because they felt too young to provide a stable environment), commitment to finishing their education, or lack of family and partner support.

Some women appeared to have made the decision to undergo a TOP without much difficulty. However, others found the process very traumatic. In arriving at their decision most women consulted their partners, friends or relatives. A few women felt strongly that there was no need to involve anyone else in this decision. However, most women had concluded this decision-making process before approaching health care professionals.

"I was like OK about it because all I knew was that I didn't want to have a baby at all and it is just not right with my life at the moment ... I'm not really a baby person ... so like having it done didn't really bother me".

"We sat down and discussed it 'cause I worked ... and we couldn't afford to have another child and give up work. So

Table 1 Age of respondents

\begin{tabular}{ll}
\hline Age range (years) & $\begin{array}{l}\text { Respondents in this } \\
\text { age range (n) }\end{array}$ \\
\hline $16-20$ & 2 \\
$21-25$ & 8 \\
$26-30$ & 1 \\
$31-35$ & 6 \\
$36-40$ & 3 \\
Not known & 1 \\
\hline
\end{tabular}


we made the decision to have a termination and we went through with it, it's a horrible decision to make together".

\section{The referral process}

Most women bought pregnancy tests from pharmacies and confirmed their pregnancy at home before contacting the health service. A few approached their GP, FPC, Brook clinic or hospital casualty department to confirm the pregnancy. For the majority of women the reason for approaching the health service was for information and referral for abortion.

"I don't want children, I never have, that didn't change my mind and so it was just a case of having to go to my doctor go through the procedures and finding out how long it would take for me to have the procedure done...."

Many women were keen to have the procedure done quickly and some commented on unnecessary delays during the referral process.

"I mean if I have my money I just walk into XX [a private provider] and I get it done. I wouldn't need to go through all this see this and see that."

Some GPs referred women elsewhere for confirmation of pregnancy, for example, asking them to buy pregnancy tests over the counter, referring them to Brook clinics, or sending urine samples to a hospital laboratory with results taking up to 5 days.

"Yeah 'cause he [the GP] said if I do it at the GP I would have to wait 5 days as they send the sample to the hospital. And I didn't want to wait 5 days, I wanted to know today. So he said I needed to go to Brook."

The woman quoted above was referred on by the Brook clinic for counselling before referral but felt this to be unnecessary and returned to her GP. Some women were asked by their GP to think about their decision and return another day, and some health professionals avoided discussing the options available following a positive pregnancy test.

"When she [the family planning nurse] told me I was pregnant I just went 'Oh dear' and she said, 'What are you going to do?' and I said 'I don't know', that was it ... well basically, she said that I should go and see my GP."

Further difficulties faced by women who had recently moved into the area included not being registered with a GP, difficulties finding a GP, and lack of awareness about alternative routes for referral.

"When I arrived here I went to the hospital emergency and he gave me a paper with a number. He said I need a doctor. When I called it was not possible in the area because all are full."

Some women complained about the difficulty in getting urgent appointments with their GPs.

"The problem with the surgery is they no longer have a walk in, which I don't quite understand why that's happened because even though it's not a total emergency, it is. What do you take as an emergency?"

These unnecessary delays caused our respondents significant distress. This was compounded by the difficulties experienced in making contact with the telephone booking system.

"So kept calling them, actually for about 4-5 days, I was keeping calling and stuff, and then I got a date and so I was happy. But I was thinking in that time when it was engaged, oh I'm not going to get it, oh my god, this thing's getting bigger and bigger, what am I going to do."
For women who had found the decision-making process difficult, such delays acted as a deterrent, making them think again about their decision and so causing further mental anguish.

"It was actually one of the most frustrating things, especially if you're dealing with, trying to make a difficult decision. I think that might actually deter other people and make them sort of say, 'Forget this, I've tried once, I've tried twice, I'm not gonna try this again'.”

From this study, we do not know how many women actually abandoned the process or sought abortion privately.

Making the decision: the role of health professionals Most women visited their doctor to ask for information and referral. They expected their doctor to support their decision but not be involved in the decision-making process.

"She [the GP] obviously realised that I'd said I knew what I wanted and she was hardly going to twist my arm around and try to change my mind and I respected her for that because I don't think I would have wanted someone to at 32 years old telling me whether or not I'm making the right decision."

Even the one couple who reported visiting their GP while unsure (and in conflict) about their decision did so in order to get information about the medical risks associated with TOP rather than for help with decision making.

We documented considerable variation in the extent to which referring doctors discussed with women about their decision to undergo an abortion. The process did not appear to be responsive to women's needs as some individuals who wished a discussion were not given this option while others who did not were expected to discuss their decision in detail. When there were discussions, few women objected if the doctors were non-judgemental in their approach but women were very upset by anything that suggested that the doctor did not support their decision.

"I was very upset but she [the GP] was very supportive ... she did spend a lot of time talking to me - I think she wanted to make sure I wasn't rushing into it for the wrong reasons but I didn't feel like she was surveying me one way or the other."

"He [the GP] didn't even discuss anything, he wrote out a letter in silence, he wouldn't even speak to me and gave me a list, a yellow list with all the information and different offices you can go to. And that was it, completely alienated."

Making the decision: the role of counselling

The role of counselling remained unclear to some women who viewed it with suspicion as an attempt to change their mind or to question their decisions, although most did not object to counselling if they felt their decisions to be respected.

"I wouldn't be here if I didn't know my own mind and I'm telling how I feel so I don't need you to question me about it, just accept it. And if I change my mind I'll tell you but I certainly don't need you to question me about whether or not I'm doing the right thing."

"Like there was no doubt you know that that was what I wanted, they did not try to say like are you sure or not. Which was good they were just accepting that I was cool, and that was what I wanted to do."

However, there was a small group of people for whom counselling was very important. For those women who did 
not tell friends and family about the pregnancy, it provided their only opportunity to discuss the decision to have an abortion.

"Even my own mum never knew my problem. I couldn't even go to my mum about it I was scared, even my dad. So when I came to them they made me speak out and they solve my problem for me. I was so glad."

One woman felt after the abortion that she had made the wrong decision and felt let down by the counselling process.

"When I spoke to the doctor the first time ... she said I would have to see a counsellor and I didn't feel like I needed to see a counsellor. I don't know what the counsellor was supposed to do for me, if she was meant to make me change my mind but she didn't make anything better ... I wish I'd changed my mind."

\section{Discussion}

An important finding from our study on the process of referral for abortion is the individual variation between women's need for support during the decision-making process and the unresponsive nature of the system currently available to meet this need. Those women who wished for supportive listening from health professionals or in-depth counselling often did not receive this while those women who required no help during the decision-making process were often required to discuss their situation on several occasions. Our data suggest that the resources currently available for supporting decision making prior to TOP need to be better targeted.

Health professionals should be more aware that most women seeking abortion have already made a firm decision and require no help in this regard, a view supported by others. ${ }^{10,18}$ In this situation we suggest that health professionals should provide information and referral only. Where doctors enquire about the reasons for the request for abortion to ensure compliance with the law, they should make their intention explicit to clients so that they are not mistakenly construed as being intrusive. It is also necessary to be aware that some women do value an opportunity for discussion and health professionals should either respond to this or refer if necessary.

In the area studied, most women receive an opportunity for brief and apparently superficial counselling. Our data suggest that many women do not value this opportunity and that it is too superficial to help some individuals who really need it. Reserving counselling for the few women who require it would free resources to ensure a high-quality service provided by trained counsellors. These observations support recently published anecdotal experience elsewhere regarding the infrequent requirement for in-depth counselling. ${ }^{19}$

Our data suggest that referral for abortion can be unnecessarily slow. This has also been reported in other studies. ${ }^{10,11}$ In some cases health professionals in primary care referred women elsewhere for pregnancy tests which reflects a failure to meet the standards for Level 1 services set out in the National Strategy for Sexual Health and HIV. ${ }^{3}$ The option for self-referral, available in the area studied, has many advantages including access to local residents not registered with GPs or not willing to approach their GP with a request for abortion. This option does not, however, appear to be well publicised both to health professionals and the general public and this needs to be addressed. We also suggest that centralised telephone booking services require close audit to monitor quality and ease of access.

Although the sample researched in this study could potentially be viewed as self-selecting on account of the attrition rate during recruitment, the findings are validated by concurrence with other studies 10,11 and that of a recently commissioned review of the local telephone booking service, which identified long queues and high call abandonment rates. ${ }^{20}$

This study, conducted in an area with an ethnically diverse population, did not include women who could not speak English due to reasons alluded to previously. These women's problems in the context of the service studied are likely to be of greater magnitude and merit further research. This study also does not shed light on the experiences of women who gave up trying to access NHS help and probably referred themselves privately, which could be a focus for further study.

We suggest that the findings of this study could form the basis for improving local service delivery around the expectations of clients.

\section{Acknowledgements}

The authors are grateful to the staff from the three abortion provider units in the area studied for their co-operation in this study and to the women who kindly agreed to take part in the study.

\section{Statements on funding and competing interests}

Funding. This study was funded by the Guy's and St Thomas' Charitable Foundation.

Competing interests. None identified.

\section{References}

1 Royal College of Obstetricians and Gynaecologists (RCOG). The Care of Women Requesting Induced Abortion. Evidence-based Guideline No. 7. London: RCOG, 2000.

2 Birth Control Trust. Abortion Provision in Britain - How Services are Provided and How They Could be Improved. London: Birth Control Trust, 1997.

3 Department of Health. National Sexual Health Strategy. London: Department of Health, July 2001.

4 Royal College of Obstetricians and Gynaecologists (RCOG). National Audit of Induced Abortion 2000 - Report of England and Wales. London: RCOG, September 2001

5 Department of Health. The NHS Plan. London: Department of Health, July 2000.

6 Slade P, Heke S, Fletcher J, et al. Termination of pregnancy: patients' perceptions of care. J Fam Plann Reprod Health Care 2001; 27 72-77.

7 Guilbert J, Roter D. Assessment of satisfaction with induced abortion procedure. J Psychol 1997; 131: 157-166.

8 Sihvo S, Hemminki E, Kosunen E, et al. Quality of care in abortion services in Finland. Acta Obstet Gynecol Scand 1998; 77: 210-217.

9 Zapka JG, Lemon S, Peterson LE, et al. The silent consumer: women's reports of abortion services. Med Care 2001; 39: 50-60.

10 Clarke L, Farrell C, Beaumont B. Camden Abortion Study - The Views and Experiences of Women Having NHS and Private Treatment. London: British Pregnancy Advisory Service, 1983.

11 Harden A, Ogden J. Young women's experiences of arranging and having abortions. Sociol Health Illn 1999; 21: 426-444.

12 McIntyre M, Anderson B, McDonald C. The intersection of relational and cultural narratives: women's abortion experiences. Can J Nurs Res 2001; 33: 47-62.

13 Ritchie J, Lewis J, Elam G. Designing and selecting samples. In: Ritchie J, Lewis J (eds), Qualitative Research Practice - A Guide For Social Science Students and Researchers. London: Sage Publications, 2003; 77-108.

14 Britten N. Qualitative interviews in health care research. In: Pope C, Mays N (eds), Qualitative Research in Health Care (2nd edn). London: BMJ Books, 2000, 11-19.

15 Ritchie J, Spencer L, O'Connor W. Carrying out qualitative analysis. In: Ritchie J, Lewis J (eds), Qualitative Research Practice -A Guide for Social Science Students and Researchers. London: Sage Publications, 2003; 219-262.

16 Pope C, Ziebland S, Mays N. Analysing qualitative data. In: Pope C, Mays N (eds), Qualitative Research in Health Care (2nd edn). London: BMJ Books, 2000, 75-88.

17 Kumar U, Baraitser P, Morton S, et al. Peri-abortion contraception: a qualitative study of users' experiences. J Fam Plann Reprod Health Care 2004; 30: 55-56.

18 Allen I. Counselling Services for Sterilisation, Vasectomy and Termination of Pregnancy. Publication No. 641. London: Policy Studies Institute, 1985

19 Matthews P, Ball S. Counselling, psychological morbidity and termination of pregnancy. J Fam Plann Reprod Health Care 2003: 29(1): 39 .

20 Turner A. A Review of the Lambeth, Southwark and Lewisham (LSL) Central Information and Booking Service (CIBS) for Termination of Pregnancy (TOP). London: Southwark Primary Care Trust, June 2003. 